\title{
A cephalometric comparison of skulls
}

\author{
A cephalometric comparison of skulls from the fourteenth, sixteenth and twentieth centuries \\ W. P. Rock, A. M. Sabieha and R. I. W. Evans Br Dent J 2006; 200: 33-37
}

\begin{abstract}
Objectives
To evaluate changes in the size and shape of the skull and jaws in British populations between the thirteenth and twentieth centuries. Method

Lateral cephalometric radiograms were obtained from skulls of three groups of subjects; 30 skulls were from the remains of those who died in the London Black Death epidemic of 1348, 54 skulls were recovered from the wreck of the Mary Rose which sank in 1545 and 31 skulls were representative of modern cephalometric values.

Results

Horizontal measurements in the base of the anterior cranial fossa and in the maxillary complex were greater in the modern group than in the medieval skulls. Cranial vault measurements were significantly higher $(P=0.000)$ in the twentieth century skulls, especially in the anterior cranial fossa.

Conclusion

Results suggest that our medieval ancestors had more prominent faces and smaller cranial vaults than modern man.
\end{abstract}

\section{IN BRIEF}

- This paper shows changes in the form and size of the skull and jaws over a period of 676 years.

- Cranial vault measurements increased by $10 \mathrm{~mm}$ between the fourteenth and twentieth centuries.

- The face has become more retruded in relation to the forehead.

\section{COMMENT}

How and why we look the way we do is arguably the biggest question of them all. Most of us think of the 'we' as our species, that static end point of mosaic evolutionary influences that have beguiled comparative anatomists, molecular biologists and alike for decades. Rock, Sabieha and Evans' paper serves as a timely reminder that we are not the full stop at the end of this evolutionary story but rather a comma.

The paper describes the investigation of 115 skulls spanning six centuries of human history. After exhaustive statistical analyses of 20 linear and angular measurements computed from a suite of 11 landmarks, the authors demonstrate that the skulls of our ancestors that sailed the seas on the Mary Rose or died of the Black Death in London are remarkably dissimilar from those of modern populations. Most notably, the paper reports that by comparison the modern face is less prognathic, the cranium is taller, and the cranial base is much longer.

These findings appeal to me on two levels. They indicate that we have changed, are changing and will continue to change with the passage of time, like any other species on this planet. To understand how modern humans evolved from the Great Ape lineage over geological time it is important to appreciate how we adapt over shorter, historical time spans. Perhaps more relevant to the readership of this eminent journal is that by helping us to comprehend the trajectory and direction of our recent morphological past, this paper offers further insights into the aetiologies of increasingly prevalent conditions like dental crowding.

My only criticisms are these: first, size scaling is overlooked. Allometry is a mischievous effect that can alter size and shape without making its presence known to the investigator. Small people have smaller heads and medieval peoples tended to be shorter than their modern descendants. Second, there is very little in the way of a discussion of possible explanations for the observed differences. I would have liked the authors to have waxed lyrical about shifts in population genetics coupled with changes in the biomechanical demands and nutritional value of the medieval diet compared with modern ostentatious tastes. But there again I probably would have complained if they had. In all, this is a great paper and I look forward to reading similar work from this team in the future.

N. S. Jeffery, Lecturer in Anatomy, Department of Human Anatomy and Cell Biology, University of Liverpool

doi: 10.1038/sj.bdj.4813119 